DOI: $10.5965 / 223811711432015210$

\title{
Enraizamento de estacas de Tibouchina moricandiana var. vinacea em função da forma de aplicação e concentrações de AIB
}

Rooting of cuttings of Tibouchina moricandiana. var. vinacea in function of the form of application and concentrations of IBA

\section{Mariane de Oliveira Pereira ${ }^{1}$, Jeniffer Grabias ${ }^{1}$, Katia Christina Zuffelatto-Ribas ${ }^{1}$ e Marcio Carlos Navroski ${ }^{2}$}

Recebido em 01/04/2015 / Aceito em 08/07/2015

\section{RESUMO}

Tibouchina moricandiana Baill. var. vinacea Handro é um arbusto lenhoso, nativo do Brasil com grande potencial ornamental. Objetivou-se neste trabalho avaliar a viabilidade da estaquia na propagação vegetativa da espécie em função da forma de aplicação e diferentes concentrações de ácido indol butírico (AIB). Estacas semilenhosas foram tratadas com $0,1.000$ e $2.000 \mathrm{mg} \mathrm{kg}^{-1} / \mathrm{mg} \mathrm{L}^{-1}$ de AIB na forma de talco e solução aquosa. Após 56 dias da aplicação dos tratamentos as estacas foram avaliadas quanto às porcentagens de enraizamento, estacas com calos, sobrevivência, mortalidade, retenção foliar, brotações novas; número de raízes por estaca e comprimento das três maiores raízes. A porcentagem de enraizamento das estacas caulinares de $T$. moricandiana foi influenciada negativamente pelas concentrações de AIB nem pela forma de aplicação. A espécie possui alta taxa de enraizamento (90,8\%), mostrando ser uma espécie com potencialidade para a propagação vegetativa via estaquia. A forma de aplicação e concentração do AIB apresentaram influência em outras variáveis, o uso de $2.000 \mathrm{mg} \mathrm{kg}^{-1}$ de AIB aplicado em talco ocasionou a diminuição do número de raízes e proporcionou o maior número de estacas vivas e não enraizadas. O comprimento das três maiores raízes por estaca foi maior com o uso de $1.000 \mathrm{mg} \mathrm{L}^{-1}$ ou $\mathrm{mg} \mathrm{kg}^{-1}$ de AIB. O uso de AIB no enraizamento das estacas pode ser dispensável, porém pode ser utilizado na concentração de $1.000 \mathrm{mg} \mathrm{L}^{-1}$ ou $\mathrm{mg} \mathrm{kg}{ }^{-1}$, aumentando-se o comprimento e o número de raízes.
PALAVRAS-CHAVE: quaresmeira, propagação vegetativa, estaquia, auxina.

\begin{abstract}
Tibouchina moricandiana Baill. var. vinacea Handro is a woody shrub, native to Brazil with ornamental potential. The objective of this study was to evaluate the feasibility of cutting the vegetative propagation of the species according to the application form and different concentrations of indole butyric acid (IBA). Softwood cuttings were treated with $0,1,000$ and $2,000 \mathrm{mg} \mathrm{kg}^{-1} / \mathrm{mg} \mathrm{L}^{-1}$ of IBA in powder and solution form. After 56 days the treatments were evaluated for rooting, cuttings with callus, survival, mortality, leaf retention, new shoots, number of roots per cutting and root length. The rooting of stem cuttings of $T$. moricandiana was negatively influenced by the concentrations of IBA or by way of application. The species has a high strike rate $(90.8 \%)$, demonstrating a species with potential for vegetative propagation through cuttings. The form of application and concentration of IBA influenced other variables. The use of 2,000 $\mathrm{mg} \mathrm{kg}^{-1}$ IBA applied by talc demonstrated a decrease in the number of roots and provided the greatest number of and unrooted live cuttings. The length of the three longest roots per cutting was higher with the use of $1,000 \mathrm{mg} \mathrm{L}^{-1}$ or $\mathrm{mg} \mathrm{kg}^{-1}$ of IBA. The use of IBA for the rooting of cuttings can be dispensed with, but can be used at a concentration of $1,000 \mathrm{mg}^{-1}$ or $\mathrm{mg} \mathrm{kg}^{-1}$ to increase the length and number of roots.
\end{abstract}

KEYWORDS: "quaresmeira", vegetative propagation, cutting, auxin.

\footnotetext{
${ }^{1}$ Universidade Federal do Paraná, Curitiba, PR, Brasil.

${ }^{2}$ Universidade do Estado de Santa Catarina, Lages, SC, Brasil.

*Autor para correspondência <maripereira.florestal@gmail.com>.
} 


\section{INTRODUÇÃO}

A família Melastomataceae possui cerca de 200 gêneros e 5.000 espécies, com representantes arbóreos e arbustivos, distribuídos principalmente nas regiões tropicais de todo o mundo (JOLY 2002, SOUZA \& LORENZI 2005). Ocorrem em todo o território brasileiro com cerca de 70 gêneros e 1.000 espécies (SOUZA \& LORENZI 2005). São comuns nos domínios da Amazônia, do Cerrado, incluindo formações de campos rupestres e da Mata Atlântica (GOLDENBERG et al. 2012). Entre os inúmeros representantes desta família no Brasil, o gênero Tibouchina se destaca, sendo conhecido popularmente como quaresmeira ou manacá-da-serra.

Tibouchina moricandiana Baill. var. vinacea Handro é um arbusto lenhoso, nativo do Brasil, mas pouco conhecido por ser raramente cultivado. Sua altura varia entre 1,5 e 3,0 metros, com muitas ramificações, folhas pubescentes e ovaladas avermelhadas. A inflorescência é curta e apresenta flores muito atrativas devido a sua coloração cor-devinho, as quais florescem quase durante todo o ano e, por isso, é considerada uma espécie com grande valor ornamental (LORENZI \& SOUZA 2008).

Apesar da grande representatividade no banco de sementes da Floresta Atlântica Montana, as espécies da família Melastomataceae apresentam grande número de sementes abortadas e uma baixa germinabilidade (ELISSON et al. 1993, BARROSO et al. 1999, TABARELLI \& MANTOVANI 1999), fato que pode ser creditado à ausência de embriões na semente, como observado em T. granulosa Cogn. (ZAIA \& TAKAKI 1998). LORENZI (2002) relata baixas taxas de germinação para T. candolleana (Mart. ex DC.), T. granulosa e T. mutabilis (Vell.) Cogn.

A falta de técnicas na produção de mudas para espécies nativas e, em alguns casos, a falta de viabilidade de suas sementes, indicam a propagação vegetativa como alternativa na multiplicação dessas plantas, possibilitando a manutenção das boas características das plantas matrizes e a redução do período juvenil, o que leva à antecipação do mecanismo reprodutivo (RODRIGUES 1990). Dentre as técnicas de propagação vegetativa, a estaquia revela-se como método economicamente viável para produção de novos indivíduos em curto período de tempo (PAIVA \& GOMES 1993).

A viabilidade da propagação comercial por estaquia depende da capacidade de enraizamento de cada espécie, da qualidade do sistema radicular formado e do desenvolvimento posterior da planta (NEVES et al. 2006). Segundo PIO et al. (2003), vários fatores podem influenciar o enraizamento das estacas, tanto intrínsecos, relacionados à própria planta, quanto extrínsecos, ligados às condições ambientais.

Entre os fatores internos destaca-se a concentração do regulador de crescimento que varia de acordo com a espécie, cultivar e tipo de estaca. As estacas possuem certa quantidade endógena de hormônios promotores ou inibidores de enraizamento, mas é necessário que haja um balanceamento adequado entre auxinas, giberelinas, citocininas e co-fatores de enraizamento para que haja enraizamento (HARTMANN et al. 2011). Desse modo, o fornecimento de auxina exógena pode promover alteração hormonal, favorecendo ou não o enraizamento.

Entre os diferentes efeitos que as auxinas causam na planta, está o estímulo ao crescimento da raiz, a qual é muito sensível a esse hormônio, apresentando alongamento em baixas concentrações e também no enraizamento de estacas caulinares. Neste caso, o hormônio se transloca das gemas ou das folhas para a parte basal da estaca, estimulando o enraizamento (SAMPAIO 1998).

Oobjetivo deste trabalho foi avaliar a viabilidade do uso da técnica de estaquia na propagação vegetativa de Tibouchina moricandiana var. vinacea em função da forma de aplicação e diferentes concentrações de AIB.

\section{MATERIAL E MÉTODOS}

A coleta de material vegetativo foi realizada em agosto de 2012, em um indivíduo adulto de T. moricandiana var. vinacea, localizado nas dependências do Campus III da Universidade Federal do Paraná, Centro Politécnico, no Setor de Ciências Biológicas em Curitiba, PR.

Imediatamente após serem coletadas e preparadas, as miniestacas foram acondicionadas em caixas de isopor contendo água. O período entre a confecção das miniestacas e o estaqueamento destas no substrato, dentro da casa de vegetação, foi sempre o mais reduzido possível, visando evitar a perda de turgor e a oxidação da base das miniestacas.

A técnica foi realizada utilizando-se estacas caulinares semilenhosas de aproximadamente $10 \mathrm{~cm}$ 
de comprimento, com diâmetro médio de $1,8 \mathrm{~mm}$, medido na parte central da estaca. Foi mantido um par de folhas opostas na porção apical da estaca, com as lâminas cortadas pela metade, a base foi cortada em bisel e o ápice cortado transversalmente acima da última gema lateral.

A desinfestação do material foi realizada por imersão total das estacas em solução de hipoclorito de sódio $(\mathrm{NaOCl})$ a $0,5 \%$ durante 10 minutos, sendo posteriormente lavadas em água corrente por cinco minutos. A base das estacas foi imersa em soluções hidroalcoólicas de diferentes concentrações de ácido indol butírico (AIB) por um período de 10 segundos e diretamente no pó, quando veiculadas sob a forma de talco. Os tratamentos controle foram veiculados com solução hidroalcoólica ou talco inerte isento de regulador vegetal.

O plantio foi realizado em tubetes de polipropileno com capacidade para $53 \mathrm{~cm}^{3}$, contendo vermiculita de granulometria média e casca de arroz carbonizada $(1: 1 \mathrm{v} / \mathrm{v})$ como substrato. As estacas foram mantidas em casa de vegetação climatizada Van der Hoeven $^{\circledR}$, localizada no Setor de Ciências Biológicas da Universidade Federal do Paraná, programada para $25{ }^{\circ} \mathrm{C} \pm 2{ }^{\circ} \mathrm{C}$ e $95 \%$ de umidade relativa.

Aos 56 dias após a aplicação dos tratamentos foi realizada a avaliação do experimento, sendo analisadas as seguintes variáveis: porcentagem de enraizamento (estacas com raízes de, no mínimo, 1 mm de comprimento); número de raízes por estaca (total de raízes emitidas); comprimento das raízes formadas por estaca (comprimento das três maiores raízes formadas, em $\mathrm{cm}$ ); porcentagem de estacas com calos; (estacas vivas com formação de massa celular indiferenciada na base e sem raízes); porcentagem de estacas vivas (estacas vivas que não apresentavam indução radicial nem formação de calos); porcentagem de mortalidade (estacas que se encontravam com tecidos necrosados); porcentagem de estacas com retenção foliar (estacas que mantiveram as folhas antigas) e porcentagem de brotações novas (estacas que apresentaram emissão de novas brotações).

$\mathrm{O}$ experimento foi executado em delineamento inteiramente casualizado com arranjo fatorial $3 \times 2$ dos tratamentos, sendo os níveis do fator A três concentrações diferentes de AIB (0, 1.000 e $2.000 \mathrm{mg}$ $\mathrm{L}^{-1}$ ou $\mathrm{mg} \mathrm{Kg}^{-1}$ ) e os níveis do fator $\mathrm{B}$ duas formas de aplicação (solução hidroalcoólica ou talco), com quatro repetições e 15 estacas por unidade experimental, totalizando 60 estacas por tratamento e
360 no total do experimento.

As variâncias dos tratamentos foram testadas quanto à homogeneidade pelo teste de Bartlett. Quando houve homogeneidade das variâncias os dados foram submetidos à análise de variância e quando houve diferença significativa pelo teste de F, tiveram suas médias comparadas pelo teste de Scott-Knott ao nível de $5 \%$ de probabilidade. A análise dos dados foi realizada no aplicativo SISVAR (FERREIRA 2011).

\section{RESULTADOS E DISCUSSÃO}

Para a variável porcentagem de enraizamento, não houve interação para a concentração de ácido indol butírico (AIB) e forma de aplicação (Tabela 1); também não foi observado efeito significativo para os fatores de forma isolada. Dessa forma, o enraizamento não foi influenciado pela presença de AIB e nem pelas formas de aplicação desta auxina.

A média de enraizamento foi de 90,8\%, mostrando que esta espécie possui potencialidade para a propagação vegetativa via estaquia. Resultados muito semelhantes foram observados por RIBEIRO et al. (2006), em estudo com T. cf. moricandiana, sendo que o uso do AIB não influenciou o enraizamento, pois as estacas usadas como testemunha também tiveram boa formação de raízes. Para esta espécie houve $94 \%$ de enraizamento, tanto para estacas apicais, como para estacas medianas, coletadas no mesmo ramo. No entanto, nem todas as espécies do gênero Tibouchina apresentam facilidade de enraizamento em estacas. Estudando-se a propagação vegetativa via estaquia de $T$. pulchra Cogn., verificou-se enraizamento entre $0,0 \%$ e $8,4 \%$ sem a aplicação de reguladores vegetais. As maiores porcentagens de enraizamento para esta espécie, com material coletado na primavera, estão associadas à tratamentos com $2.000 \mathrm{mg} \mathrm{L}^{-1}$ AIB e 4000 $\mathrm{mg} \mathrm{L}^{-1} \mathrm{AIB}$, correspondendo a $28 \%$ de enraizamento em ambos os tratamentos (KNAPIK et al. 2003).

Em estudo realizado com diferentes espécies de Tibouchina, analisou-se o comportamento destas espécies ao enraizamento e tornou-se evidente o sucesso das estacas de $T$. fothergillae, que enraizaram 100\%, seguidas da T. sellowiana e T. pulchra, com $57,50 \%$ e $26,67 \%$, respectivamente, e da $T$. granulosa com apenas $16,67 \%$ de enraizamento (BORTOLINI et al. 2008a).

Existem respostas diferentes entre espécies e variedades da mesma espécie quanto à utilização de reguladores vegetais (MITRA \& BOSE 1991). Isto 
Tabela 1- Porcentagem de enraizamento, número de raízes e comprimento das raízes por estaca enraizada de Tibouchina moricandiana var vinacea, após 56 dias de estaqueamento, em função de diferentes concentrações de AIB $\left(0,1.000\right.$ e $\left.2.000 \mathrm{mg} \mathrm{kg}^{-1} / \mathrm{mg} \mathrm{L}^{-1}\right)$ e duas formas de aplicação (solução e talco).

Table 1- Percentage of rooting, number of roots and length of roots per rooted cutting of Tibouchina moricandiana var vinacea, after 56 days of staking, according to different concentrations of IBA (0, 1,000 e 2,000 $\mathrm{mg} \mathrm{kg}^{-1} / \mathrm{mg} \mathrm{L}^{-1)}$ and two application forms (solution and talc).

\begin{tabular}{|c|c|c|c|c|c|}
\hline \multirow{2}{*}{ Variável } & \multirow{2}{*}{$\begin{array}{l}\text { Forma de } \\
\text { aplicação }\end{array}$} & \multicolumn{3}{|c|}{ Concentrações de $\mathrm{AIB}\left(\mathrm{mg} \mathrm{L}^{-1}\right.$ ou $\left.\mathrm{mg} \mathrm{kg}^{-1}\right)$} & \multirow{2}{*}{ Médias } \\
\hline & & 0 & 1.000 & 2.000 & \\
\hline \multirow{3}{*}{$\begin{array}{c}\text { Enraizamento (\%) } \\
\qquad{ }^{1} \mathrm{CV} \%=36,5\end{array}$} & Solução & 88,33 & 90,00 & 93,33 & 90,55 \\
\hline & Talco & 91,67 & 95,00 & 86,67 & 91,11 \\
\hline & Média & 90,00 & 92,50 & 90,00 & - \\
\hline \multirow{3}{*}{$\begin{array}{c}\mathrm{N}^{\mathrm{o}} \text { raízes } \\
\mathrm{CV} \%=43,4\end{array}$} & Solução & $7,22 \mathrm{Aa}^{*}$ & $7,72 \mathrm{Aa}$ & $8,42 \mathrm{Aa}$ & 7,78 \\
\hline & Talco & $7,17 \mathrm{Aa}$ & $6,57 \mathrm{Aa}$ & $5,28 \mathrm{Bb}$ & 6,34 \\
\hline & Média & 7,19 & 7,14 & 6,85 & - \\
\hline \multirow{3}{*}{$\begin{array}{l}\text { Comprimento } \\
\text { raízes }(\mathrm{cm}) \\
\mathrm{CV} \%=33,8\end{array}$} & Solução & 3,58 & 3,93 & 3,04 & 3,61 \\
\hline & Talco & 3,45 & 4,24 & 3,33 & 3,61 \\
\hline & Média & $3,52 \mathrm{~b}$ & $4,09 \mathrm{a}$ & $3,18 \mathrm{~b}$ & - \\
\hline
\end{tabular}

*Médias seguidas pela mesma letra maiúscula na coluna e minúscula na linha não diferem entre si pelo teste de Scott-Knott, a 5\% de probabilidade de erro. ${ }^{1} \mathrm{CV} \%=$ coeficiente de variação.

pode ser devido ao balanço endógeno entre auxinas/ citocininas, pois um equilíbrio da relação em favor das citocininas provoca o início do desenvolvimento das brotações. Além disso, a habilidade ao enraizamento de uma estaca caulinar é determinada pelo balanço entre fatores nutricionais e hormonais e o enraizamento pode vir a não ocorrer quando a concentração de um destes estiver muito alta (NANDA et al. 1971).

Para o número de raízes por estaca, a interação entre os fatores concentração e forma de aplicação foi significativa, indicando que os fatores não são independentes. Já para a variável comprimento médio das três maiores raízes por estaca, a análise de variância revelou que os fatores são independentes e que apenas a concentração utilizada apresentou efeito significativo.

$\mathrm{O}$ número de raízes foi influenciado pela concentração de AIB e pela forma de aplicação (Tabela 1). O menor número de raízes foi encontrado utilizando-se $2.000 \mathrm{mg} \mathrm{Kg}^{-1}$ de AIB aplicado na forma de talco. O maior número de raízes, aplicando-se na forma de solução foi encontrado com $2.000 \mathrm{mg} \mathrm{L}^{-1}$, não diferindo dos demais tratamentos, inclusive da ausência de AIB. Já com a utilização de AIB em talco, a concentração de $2.000 \mathrm{mg} \mathrm{Kg}^{-1}$ provocou a diminuição do número de raízes, demonstrando que o uso de AIB em talco em concentrações mais altas pode provocar toxicidade à estaca. A ausência de AIB apresentou boa formação de raízes, evidenciando que o uso da auxina pode ser privado, reduzindo-se os custos.

Em trabalho com a espécie $T$. fothergillae foram encontradas respostas diferentes às deste estudo quanto ao uso de AIB na formação de raízes, em que o maior número foi obtido com concentrações mais elevadas de AIB (1.600 $\left.\mathrm{mg} \mathrm{L}^{-1}\right)$ (RODRIGUES et al. 2011). Os autores concluem que apesar do AIB proporcionar enraizamento, não se justifica o seu uso para a espécie em estudo, fato que também foi observado com T. moricandiana var. vinacea.

Para T. sellowiana, também foi encontrada resposta diferente a deste estudo. Em estacas coletadas no inverno (mesma época de coleta deste trabalho) o melhor resultado no número de raízes formadas $(5,0)$ foi para $3.000 \mathrm{mg} \mathrm{kg}^{-1}$ de AIB em talco (BORTOLINI et al. 2008b). Além de fatores extrínsecos como umidade, temperatura, luminosidade, substratos, tipos de estacas e épocas do ano, a formação de raízes varia de acordo com a espécie e cultivar (RODRIGUES et al. 2011). Dessa forma o uso de AIB no enraizamento de estacas possui um comportamento específico para cada espécie do gênero Tibouchina.

Para o comprimento médio das três maiores raízes por estaca, o melhor tratamento foi obtido para a concentração de $1.000 \mathrm{mg} \mathrm{L}^{-1}$ (ou mg kg-1) de AIB com $4,09 \mathrm{~cm}$, diferindo estatisticamente da testemunha com 3,52 cm e com o uso de AIB na concentração de $2.000 \mathrm{mg} \mathrm{L}^{-1}$ (ou mg kg${ }^{-1}$ ) com 3,18 cm (Tabela 1). 
Quanto ao comprimento médio de raízes por estaca, foi encontrada resposta semelhante para Tibouchina sellowiana. O tratamento com $1.000 \mathrm{mg}$ $\mathrm{L}^{-1}$ de AIB teve um maior valor $(1,4 \mathrm{~cm})$ diferenciando dos demais tratamentos. $\mathrm{O}$ aumento da concentração de $\operatorname{AIB}\left(2.000 \mathrm{mg} \mathrm{L}^{-1}\right)$ ocasionou a diminuição do comprimento médio de raízes (VIEIRA 2011), fato que corrobora os resultados deste trabalho. Em outro estudo com estacas de T. sellowiana, o maior comprimento das três maiores raízes foi obtido na concentração de $3.000 \mathrm{mg} \mathrm{L}^{-1}$ de AIB (solução), com estacas coletadas durante o verão, apresentando média de 12,35 cm (BORTOLINI et al. 2008b).

Para a variável porcentagem de estacas vivas houve interação entre os fatores (concentração e forma de aplicação de AIB) (Tabela 2). Não houve influência na aplicação via solução em função da concentração de AIB, não havendo também na forma de talco.

Observa-se diferença significativa para a concentração de $2.000 \mathrm{mg} \mathrm{kg}^{-1}$ na forma de aplicação, sendo que nesta concentração de AIB não houve estacas vivas e não enraizadas quando houve a aplicação via solução. Já com o uso de talco, houve mais de $8 \%$ de estacas vivas, mas sem formação de raízes. Isto pode indicar que quando se faz o uso de AIB aplicado via talco pode haver uma maior demora no enraizamento, pois as estacas continuam vivas, podendo enraizar posteriormente.

Variações de tempo e concentrações podem ser benéficas à iniciação radicial ou, dependendo do caso, tóxicas ao material vegetativo. A aplicação via talco é simples, entretanto, devido a variações no material aderido a base da estaca, pode não ser uma alternativa viável, podendo causar muitas vezes toxicidade, prejudicando o enraizamento (ONO \& RODRIGUES 1996). Para estacas de T. pulchra também não houve diferença estatística entre os tratamentos, mas, numericamente, a maior porcentagem de sobrevivência foi registrada para $4.000 \mathrm{mg} \mathrm{L}^{-1}$ AIB (30,00\%) (KNAPIK et al. 2003).

Para as variáveis porcentagem de estacas mortas, porcentagem de estacas com retenção foliar e porcentagem de brotações novas não houve interação para a concentração de AIB e forma de aplicação; também não foi observado efeito significativo para os fatores de forma isolada (Tabela 2).

Numericamente (sem diferença estatística), a aplicação via solução, na ausência de AIB, teve a maior porcentagem de estacas mortas $(8,33 \%)$.

Tabela 2 - Porcentagem de estacas vivas, estacas mortas, folhas antigas e brotações novas por estaca de Tibouchina moricandiana var vinacea, após 56 dias de estaqueamento, em função de diferentes concentrações de AIB (0, 1.000 e $\left.2.000 \mathrm{mg} \mathrm{kg}^{-1} / \mathrm{mg} \mathrm{L}^{-1}\right)$ e duas formas de aplicação (solução e talco).

Table 2 - Percentage of live cuttings, dead cuttings, old leaves and new shoots by cutting Tibouchina moricandiana var vinacea, after 56 days of staking, according to different concentrations of IBA ( 0 , 1,000 e 2,000 $\mathrm{mg} \mathrm{kg}^{-1} / \mathrm{mg} \mathrm{L}^{-1}$ ) and two application forms (solution and talc).

\begin{tabular}{|c|c|c|c|c|c|}
\hline \multirow{2}{*}{ Variável } & \multirow{2}{*}{$\begin{array}{l}\text { Forma de } \\
\text { aplicação }\end{array}$} & \multicolumn{3}{|c|}{ Concentrações de AIB $\left(\mathrm{mg} \mathrm{L}^{-1}\right.$ ou $\left.\mathrm{mg} \mathrm{kg}^{-1}\right)$} & \multirow{2}{*}{ Médias } \\
\hline & & 0 & 1.000 & 2.000 & \\
\hline \multirow{3}{*}{$\begin{array}{c}\text { Estacas vivas }(\%) \\
{ }^{1} \mathrm{CV} \%=21,5\end{array}$} & Solução & $3,33 \mathrm{Aa}^{*}$ & $5,00 \mathrm{Aa}$ & $0,00 \mathrm{Aa}$ & 2,78 \\
\hline & Talco & 3,33 Aa & $1,67 \mathrm{Aa}$ & $8,33 \mathrm{Ab}$ & 4,44 \\
\hline & Média & 3,33 & 3,33 & 4,16 & - \\
\hline \multirow{3}{*}{$\begin{array}{c}\text { Estacas mortas }(\%) \\
\mathrm{CV} \%=43,6\end{array}$} & Solução & 8,33 & 5,00 & 6,67 & 6,67 \\
\hline & Talco & 5,00 & 3,33 & 5,00 & 4,44 \\
\hline & Média & 6,67 & 4,17 & 5,83 & - \\
\hline \multirow{3}{*}{$\begin{array}{c}\text { Folhas antigas }(\%) \\
\qquad \mathrm{CV} \%=37,1\end{array}$} & Solução & 10,00 & 16,67 & 10,00 & 12,20 \\
\hline & Talco & 16,67 & 10,00 & 3,33 & 10,00 \\
\hline & Média & 13,33 & 13,33 & 6,67 & - \\
\hline \multirow{3}{*}{$\begin{array}{c}\text { Brotações novas } \\
(\%) \\
\text { CV\% } \% 25,6\end{array}$} & Solução & 93,33 & 96,67 & 90,00 & 93,33 \\
\hline & Talco & 95,00 & 95,00 & 93,33 & 94,44 \\
\hline & Média & 94,17 & 95,83 & 91,67 & - \\
\hline
\end{tabular}

*Médias seguidas pela mesma letra maiúscula na coluna e minúscula na linha não diferem entre si pelo teste de Scott-Knott, a 5\% de probabilidade de erro. ${ }^{1} \mathrm{CV} \%=$ coeficiente de variação. 
Independente da concentração de AIB utilizada, a aplicação via solução apresentou maior taxa de mortalidade de estacas quando comparado ao uso de talco. $\mathrm{O}$ número médio de estacas que mantiveram folhas antigas foi de $11,11 \%$, e $93,9 \%$ das estacas apresentaram brotações novas.

A presença de folhas pode constituir um fator importante no enraizamento de estacas. Segundo MAYER \& PEREIRA (2003), em trabalho realizado com umezeiro, verificaram que a retenção de folhas nas estacas influenciou a velocidade de enraizamento, enquanto que a ausência de folhas resultou praticamente, em estacas com calo ou mortas. Em T. moricandiana var. vinacea se observou uma rápida queda das folhas velhas, surgindo brotações jovens. Apesar de não haver diferença estatística, pode-se observar que houve uma maior tendência de enraizamento e porcentagem de estacas com brotações novas com o uso de $1.000 \mathrm{mg} \mathrm{L}^{-1}$ (ou mg kg-1) de AIB.

Não houve o aparecimento de calos nas estacas de Tibouchina moricandiana var. vinacea. Comumente, quando as estacas são induzidas ao enraizamento, ocorre a formação de calos, por meio das quais as raízes emergem. Porém, a formação das raízes adventícias e dos calos são processos independentes e sua ocorrência simultânea se explica pelo fato de que em ambos ocorre o processo de divisão celular, o que pode depender de condições internas e ambientais similares (HARTMANN et al. 2011). Neste trabalho foi observada a formação de raízes diretamente da estaca, sem a formação de calos.

Embora a calogênese seja um evento fisiológico interessante como precursor da formação de raízes em muitas espécies, principalmente coníferas, ERIG \& SCHUCH (2005) relatam que a formação de calos na zona de enraizamento é indesejável, pois pode afetar a qualidade das raízes, principalmente no que se refere à conexão vascular com a planta. Dessa forma, o enraizamento sem a presença de calos é indicado para uma boa formação de mudas por meio do processo de estaquia.

\section{CONCLUSÕES}

Nas condições em que foi realizado o presente experimento, pode-se concluir que Tibouchina moricandiana var. vinacea é uma espécie com potencialidade para a propagação vegetativa via estaquia.

$\mathrm{O}$ uso de AIB não é necessário para o enraizamento de estacas caulinares, porém sua utilização e a forma de aplicação tem influência negativa no número e comprimento de raízes e na porcentagem de estacas vivas, em determinadas situações.

\section{AGRADECIMENTOS}

Aos colegas e estagiários do GEPE pelo auxílio durante a execução do experimento e ao Departamento de Botânica da UFPR, pela estrutura física e equipamentos.

\section{REFERÊNCIAS}

BARROSO GM et al. 1999. Frutos e sementes: morfologia aplicada à sistemática de dicotiledôneas. Viçosa: UFV. 443 p.

BORTOLINI MF et al. 2008a. Enraizamento de estacas caulinares de quatro espécies do gênero Tibouchina Aubl. (Melastomataceae Juss.). R B. Horticul Ornamental 14: 187-192.

BORTOLINI MF et al. 2008b. Tibouchina sellowiana (Cham.) Cogn.: enraizamento, anatomia e análises bioquímicas nas quatro estações do ano. R Ciênc Florestal 18: 159-171.

ELISSON AM et al. 1993. Seed and seedling ecology of neotropical Melastomataceae. Ecology 74: 1733-1749.

ERIG AC \& SCHUCH MW. 2005. Micropropagação fotoautotrófica e uso da luz natural. Ci Rural 35: 961-965.

FERREIRA DF. 2011. Sisvar: a computer statistical analysis system. Ciênc Agrotec 35: 1039-1042.

GOLDENBERG R et al. 2012. Taxonomia de Melastomataceae no Brasil: retrospectiva, perspectivas e chave de identificação para os gêneros. Rodriguésia 63:145-161.

HARTMANN HT et al. 2011. Plant propagation: principles and practices. 8th. ed. Boston: Prentice-Hall, 915 p.

JOLY AB. 2002. Botânica: introdução à taxonomia vegetal. 13. ed. São Paulo: Ed. Nacional.

KNAPIK JG et al. 2003. Influência da época de coleta e da aplicação de ácido indol butírico na propagação por estaquia da Tibouchina pulchra (Cham.) Cogn. (quaresmeira). Iheringia 58: 171-179.

LORENZI H. 2002. Árvores brasileiras: manual de identificação e cultivo de plantas arbóreas nativas do Brasil. 4. ed. Nova Odessa: Instituto Plantarum, 384 p.

LORENZI H \& SOUZA HM. 2008. Plantas ornamentais no Brasil: arbustivas, herbáceas e trepadeiras. 4.ed. Nova Odessa: Instituto Plantarum, $1088 \mathrm{p}$.

MAYER NA \& PEREIRA FM. 2003. Enraizamento de estacas herbáceas de quatro clones de umezeiro (Prunus mume Sieb. et Zucc.) durante o inverno ameno, em Jaboticabal-SP. Rev Bras Frutic 25: 505-507.

MITRA SK \& BOSE TK. 1991. Metabolic changes during adventitious root formation in Ethrel and IBA treated 
cutting of Litchi. Indian J Hortic 48: 35-48.

NANDA KK et al. 1971. Effect of glucose and auxins in rooting etiolated stem segments of Populus nigra. Physiol Plantarum 24: 387-391.

NEVES TS. et al. 2006. Enraizamento de corticeira-daserra em função do tipo de estaca e variações sazonais. Pesq Agropec Bras 41: 1699-1705.

ONO EO \& RODRIGUES JD. 1996. Aspectos da fisiologia do enraizamento de estacas caulinares. Jaboticabal: FUNEP, $83 \mathrm{p}$.

PAIVA HN \& GOMES JM. 1993. Propagação vegetativa de espécies florestais. Minas Gerais, Imprensa universitária, 40p.

PIO R. et al. 2003. Enraizamento de estacas apicais de figueira tratadas com sacarose e ácido indolbutírico por imersão rápida. Revista Bras. Agroc. 9: 35-38.

RIBEIRO MNO et al. 2006. Efeito do ácido indolbutírico sobre estacas de Tibouchina cf. moricandiana. Disponível em:www.maa.gba.gov.ar/agriculturaganaderia/ floricultura/../26.doc. Acesso em: 06 nov. 2012.

RODRIGUES VA. 1990. Propagação vegetativa de Aroeira Schinus terebinthifolius Raddi, Canela Sassafrás Ocotea pretiosa Benth \& Hook e Cedro Cedrela fissilis Vellozo através de estacas radiciais e caulinares. Dissertação (Mestrado em Engenharia Florestal). UFPR, Curitiba, 90p. RODRIGUES DS et al. 2011. Reguladores de Crescimento em Propagação de Tibouchina fothergillae (D.C.) Cogn. Anais: $18^{a}$ Reunião Anual do Instituto de Botânica. São Paulo, SP.

SAMPAIO ES. 1998. Fisiologia vegetal: teoria e experimentos. Ponta Grossa: Editora UEPG, 190 p.

SOUZA VC \& LORENZI H. 2005. Botânica sistemática: guia ilustrado para identificação das famílias de Angiospermas da flora brasileira, baseado em APG II. Nova Odessa: Instituto Plantarum, $640 \mathrm{p}$.

TABARELLI M \& MANTOVANI W. 1999. A riqueza da floresta atlântica de encosta no Estado de São Paulo (Brasil). Rev Bras Bot 22: 217-223.

VIEIRA DP. 2011. Efeitos do ácido indolbutírico (AIB) e cinetina no enraizamento de estacas em Tibouchina sellowiana (Cham.) Cong., Xylopia brasiliensis Spreng. e Ocotea catharinensis Mez. UNESC, Trabalho de conclusão de curso (Ciências Biológicas). 44 p.

ZAIA JE \& TAKAKI M. 1998. Estudo da germinação de sementes de espécies arbóreas pioneiras: Tibouchina pulcra Cogn e Tibouchina granulosa Cogn.(Melastomataceae). Acta Bot Bras 12: 221-229. 